\title{
Using Social Media to Create Customer Value Through Immersive and Satisfying Interactions: An Abstract
}

\author{
Andrew Rohm, Velitchka Kaltcheva, and Mitchell Hamilton
}

\begin{abstract}
This research examines the effects of social media brand-consumer interactions on three types of customer value: customer lifetime value (CLV), customer influence value (CIV), and customer knowledge value (CKV). By examining the differential effects of consumers' satisfaction and immersion with social media brand interactions on CLV, CIV, and CKV, the authors identify conditions under which interaction satisfaction and interaction immersion create value for brands. Results suggest that whereas interaction satisfaction positively influences both CLV and CIV, interaction immersion impacts both CIV and CKV. The authors identify social media strategies for brands related to interaction satisfaction and immersion that are based on the three types of customer value studied. The findings reported offer important managerial and theoretical implications with respect to the effects of discrete social media interactions on customer value creation.
\end{abstract}

References Available Upon Request

A. Rohm $(\bowtie) \bullet$ V. Kaltcheva $\bullet$ M. Hamilton Loyola Marymount University, Los Angeles, CA, USA

e-mail: andrew.rohm@1mu.edu; velitchka.kaltcheva@lmu.edu; mitchell.hamilton@1mu.edu 